\title{
SPONTANEOUS ESOPHAGEAL PERFORATION: WHEN NOT TO OPERATE
}

Shenthil Prabhu Murugesan ${ }^{1}$, Anbalagan Pichaimuthu², Senthil Kumar Perumal'3, Jeswanth Satyanesan, Ravichandran Palaniappan ${ }^{5}$

\section{HOW TO CITE THIS ARTICLE:}

Shenthil Prabhu Murugesan, Anbalagan Pichaimuthu, Senthil Kumar Perumal, Jeswanth Satyanesan, Ravichandran Palaniappan. "Spontaneous Esophageal Perforation: When not to Operate". Journal of Evolution of Medical and Dental Sciences 2015; Vol. 4, Issue 87, October 29; Page: 15269-15274,

DOI: $10.14260 /$ jemds $/ 2015 / 2170$

ABSTRACT: Spontaneous Oesophageal perforation is lethal unless managed appropriately. Oesophageal perforation can be spontaneous (Boerhaeve), post traumatic, malignant or foreign body induced. Appropriate treatment depends on the size of perforation, time of presentation between rupture and diagnosis and general condition of the patient. Not all patients need surgical management and when carefully selected there are subset of patients who can be managed medically. CASE REPORT: A case of spontaneous oesophageal perforation due to intense retching following alcohol intake in a 35year old male is described here with a review of pertinent literature. The patient had presented with intense retching followed by vomiting which contained undigested food particles initially only to be followed by hematemesis, chest pain, fever with left sided pleural effusion. Computed tomographic scan demonstrated a pneumomediastinum, and left sided pleural effusion. The patient was managed successfully by conservative treatment. CONCLUSION: Spontaneous oesophageal perforation can be managed conservatively in a selected set of patients.

KEYWORDS: Spontaneous esophageal perforation; Boerhaave Syndrome; conservative treatment of esophageal perforation.

INTRODUCTION: BACKGROUND: Perforation of Oesophagus can be spontaneous or due to iatrogenic causes or foreign bodies. Presentation depends on the size of disruption and time elapsed between onset of severe pain and diagnosis and whether there is a free drainage into pleural cavity. Early diagnosis and appropriate management plays a vital role in avoiding mortality.

Surgical management has been followed traditionally for spontaneous esophageal perforation. Management can be conservative or surgical depending on the cause, site, extent, symptoms, signs and radiological findings. We herein present a case of spontaneous esophageal perforation which was managed non-surgically.

CASE REPORT: A 35 year old male attended the emergency department with history of vomiting with intense retching after alcohol intake. The Vomitus contained undigested food particles and it was associated with chest pain that radiated to his back. He had presented 36hours after the onset of symptoms.

On Examination patient was febrile (Temperature $100^{\circ} \mathrm{F}$ ) and had decreased air entry in left lower zone of the chest. His blood pressure was $140 / 80 \mathrm{~mm}$ of mercury and pulse rate was 114 per minute and respiratory rate was 18per minute. Saturation in room air was 100percent. There was no surgical emphysema in supraclavicular fossa.

Examination of his abdomen revealed severe tenderness confined to upper abdomen with rigidity in epigastric region.

Laboratory values on admission were as follows: total white blood cell count: $12800 / \mu$ with neutrophilia; red blood cell count: $480 \times 10000 / \mu l$; haemoglobin: $11.6 \mathrm{gm} / \mathrm{dl}$; 


\section{CASE REPORT}

Chest $\mathrm{X}$ ray (Figure1) taken immediately revealed pneumomediastinum in retro cardiac region and there was no air under diaphragm.

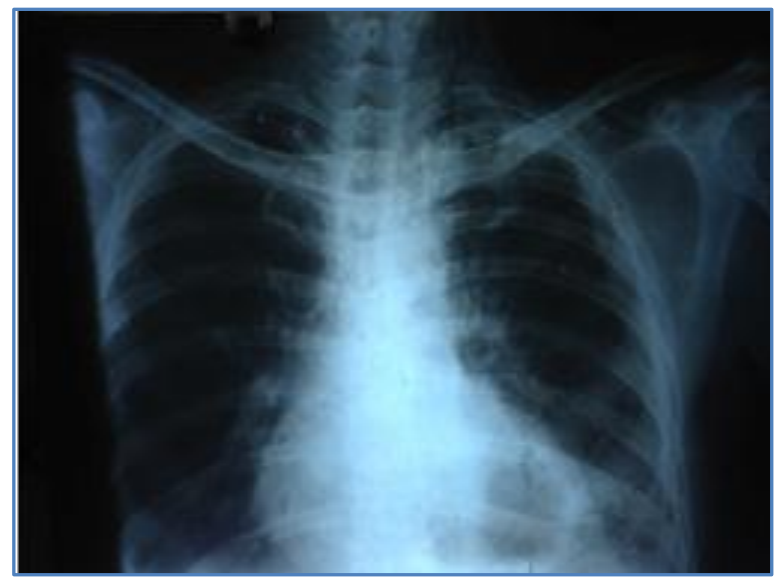

Fig. 1

Contrast enhanced Computed Tomography of chest (Figure 2) revealed pneumomediastinum with minimal left pleural effusion and lower lobe atelectasis.

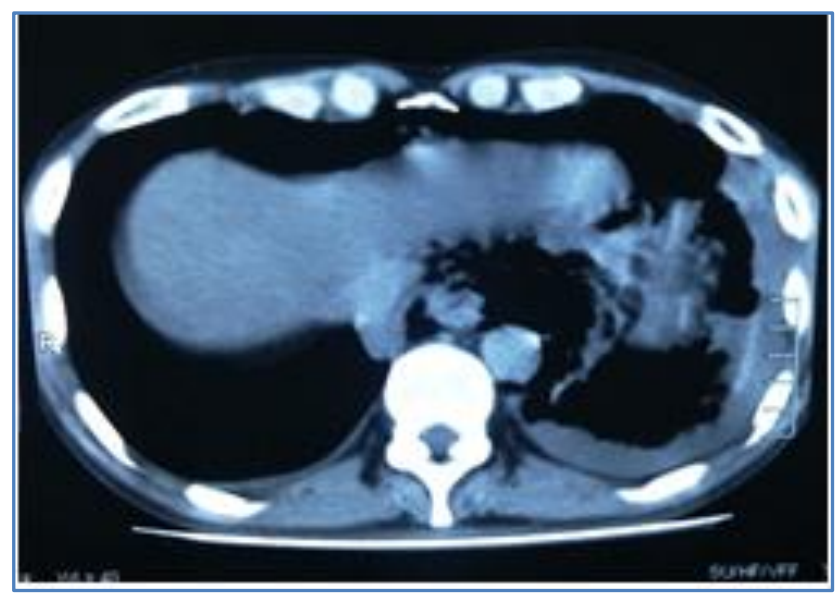

Fig. 2

As the patient was clinically stable conservative management was proposed for the patient. With a diagnosis of spontaneous esophageal perforation with delayed presentation, patient was managed with nil by mouth, continuous nasogastric drainage, intravenous fluids, total parenteral nutrition, broad spectrum intravenous antibiotics (Imepenam $2 \mathrm{~g} /$ day for 14 days and proton pump inhibitor (Omeprazole 40mg/day, intravenously for 14days).

On the third hospital day patient's vitals were as follows: BP: 110/80, Pulse rate: 84/minute; Temperature: $98.6^{\circ} \mathrm{F}$; Laboratory tests on $3^{\text {rd }}$ hospital day revealed total white blood cell count of $8500 / \mu$ l. On the fifth hospital day, oral contrast study was done which revealed extravasation of contrast into mediastinum and flow of contrast back into esophageal lumen (Figure 3 and figure 4). 


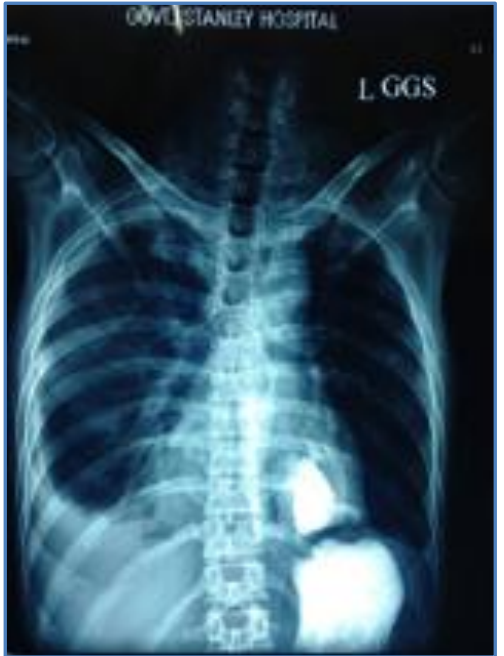

Fig. 3

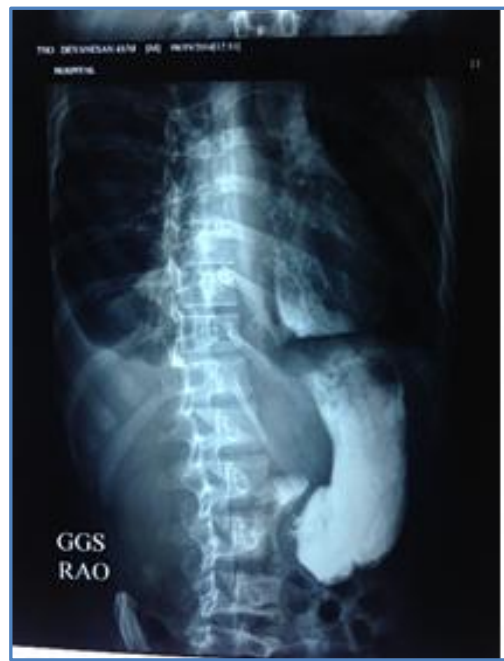

Fig. 4

On tenth hospital day a repeat chest $\mathrm{x}$ ray revealed absence of pneumomediastinum with resolution of pleural effusion. (Figure 5)

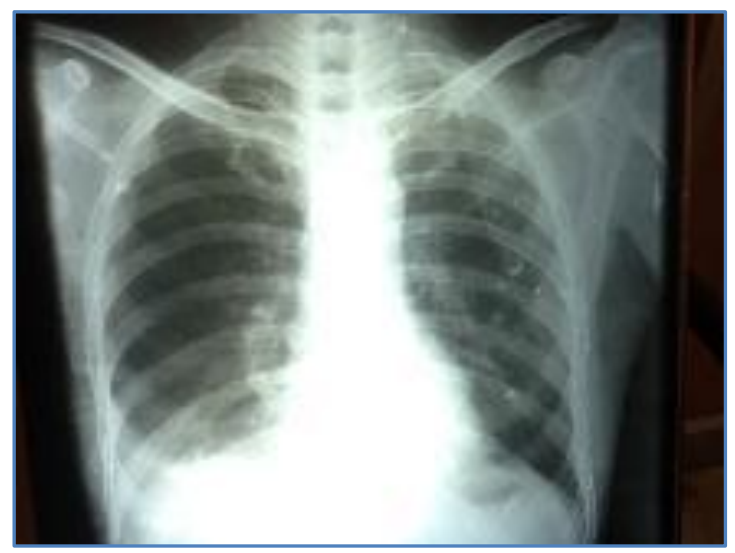

Fig. 5

On $14^{\text {th }}$ in hospital day esophagogastroscopy revealed healed ulcer in the distal esophagus. Hence patient was resumed on orals on $14^{\text {th }}$ day.

DISCUSSION: The causes of esophageal perforation can be broadly classified into three types: iatrogenic, traumatic, and spontaneous. Spontaneous esophageal rupture constitutes 20 to 40percentage of esophageal perforation. ${ }^{[1]}$ Boerhaave's syndrome, a condition described by Hermann Boerhaave in the year 1724, is a spontaneous perforation of the oesophagus due to forceful emesis.[2]

The classic site of perforation for this is the distal third of the oesophagus. Mackler's triad of subxiphoid chest pain, vomiting and subcutaneous emphysema is present only in $14 \%$ of cases.[3] It is extremely dangerous and occasionally fatal because of delayed diagnosis which is due to the nonspecific symptoms and its propensity to rapidly progress to severe mediastinitis, sepsis and multiple organ failure.[1]

The most consistent symptom of an esophageal injury is pain localised along the course of the esophagus. ${ }^{[4]}$ However, in up to one third of cases of perforated esophagus symptoms are atypical[4]. The most diagnostically useful sign is surgical emphysema. 
Esophageal perforation can be diagnosed with esophagography, esophagoscopy or Computed tomography. Chest X-rays may show mediastinal and subcutaneous emphysema, pleural fluid, and air. If taken early, the chest X-ray findings can be normal.[4]

Mediastinal emphysema can take up to 1 hour to develop, and pleural effusion can take several hours to become evident.[5] Water-soluble contrast esophagography is the diagnostic procedure of choice in patients with clinically suspected perforation of the esophagus, and this test may define the anatomical site and extent of the perforation.

False-negative esophagograms occur in $10 \%$ to $36 \%$ of perforations. Spasm, tissue oedema, and other factors may contribute to false-negative results. Furthermore, leakage may be delayed, so that an immediate esophagogram may fail to demonstrate extravasation.[6]

White et al reported that Esophagography is more sensitive than esophagoscopy in cervical esophageal perforation but for thoracic esophageal perforation both esophagography and esophagoscopy are equally effective.[7]

Esophagoscopy can also be used to observe the healing course of an esophageal perforationas in our case. One must be very cautious while performing esophagoscopy in esophageal rupture as injudicious insufflation of air might actually worsen the pneumomediastinum.

If clinical suspicion of perforation is still high even when the initial esophagogram is negative, another contrast study should be repeated after several hours to demonstrate small tears. ${ }^{[8]}$ Flexible esophagoscopy may miss $20 \%$ of injuries.

CT can be used in patients with atypical symptoms as reported by White et al.[9] Computed tomography of the chest is more sensitive in detecting mediastinal air and fluid, and may also be useful in cases in which contrast esophagograms cannot be obtained or in cases that are difficult to diagnose or localise

Early reviews.[10] have documented the successful non-operative treatment of iatrogenic and spontaneous perforations. ${ }^{[9]}$

\section{Cameron et al.[11] have reported the following criteria for conservative therapy:}

a) The esophageal disruption is confined to the mediastinum

b) The cavity is well drained into the esophagus: and

c) The patient has minimal symptoms and no evidence of clinical sepsis.

They have also reported mortality rates of $38 \%$ in patients treated surgically and of only $9 \%$ in patients treated conservatively. The original criteria suggested by Cameron et al.[11] has been modified to a more stringent approach to esophageal perforation by Altorjay et al. ${ }^{[12]}$ who recommended nonoperative treatment only for intramural perforations and Kiernan et al.[13] who suggested that conservative therapy be reserved for "microperforations" only with no ongoing leaks.

Shaffer et al.[14] have suggested alternative guidelines for the selective use of nonoperative treatment:

1) Clinically stable patients.

2) Early rupture detection, before major contamination has occurred and

3) Esophageal disruptions are well contained within the mediastinum or a pleural loculus. However, Shaffer et al.[14] has recommended surgical treatment for most cases of Boerhaave syndrome because of the high possibility of contamination. 
However Perforations of the lower two thirds of the esophagus that affect the pleura, pericardium, or peritoneum require rapid surgical intervention.[15]

Although the rupture in our patient was spontaneous, we selected conservative therapy as all the three factors suggested by Cameron et al was satisfied.

Boerhaave syndrome could be a possibility in a patient presenting with chest pain or epigastric pain following vomiting. High index of clinical suspicion, good quality chest $\mathrm{x}$ ray

Careful endoscopy and esophagogram with a water soluble contrast can help us in the diagnosis. When carefully selected spontaneous esophageal perforation can be managed nonsurgically.

\section{REFERENCES:}

1. Kim-Deobald J, Kozarek RA: Esophageal perforation:an 8-year review of a multispeciality clinic's experience. Am J Gastroenterol 1992; 87: 1112-1119.

2. Malik UF, Young R, Pham HD, McCon A, Shen B, Landres R, et al. Chronic presentation of Boerhaave's syndrome. BMC Gastroenterol 2010; 10:29.

3. Vallbo"hmer D, Ho" lscher AH, Ho" lscher M, Bludau M, Gutschow C, Stippel D, et al. Options in the management of esophageal perforation: analysis over a 12-year period. Dis Esophagus 2010; 23:185-90.

4. Kanowitz A, Markovchick V: Oesophageal and diaphragmatic trauma. In Emergency medicine: concepts and clinical practice 4th edition. Edited by: Rosen P. St Louis: Mosby; 1998:546-548.

5. Kanowitz A, Markovchick V: Oesophageal and diaphragmatic trauma. In Emergency medicine: concepts and clinical practice 4th edition. Edited by: Rosen P. St Louis: Mosby; 1998:546-548.

6. Sung SW, Park JJ, Kim YT, Kim JH: Surgery in thoracic esophageal perforation: primary repair is feasible. Dis Esophagus 2002, 15:204-209.

7. White RK, Morris DM: Diagnosis and management of esophageal perforations. Am Surg 1992; 58: $112-119$.

8. Sung SW, Park JJ, Kim YT, Kim JH: Surgery in thoracic esophageal perforation: primary repair is feasible. Dis Esophagus 2002, 15:204-209.

9. Larrieu AJ, Kieffer R. Boerhaave syndrome: report of a case treated non-operatively. Ann Surg. $1975 ; 181: 452$.

10. Cameron JL, Kieffer RF, Hendrix TR, et al. Selective nonoperative management of contained intrathoracic esophageal disruptions. Ann Thorac Surg. 1978; 27:404-408.

11. Cameron JL, Kieffer RF, Hendrix TR, Mehigan DG, Baker RR: Selective nonoperative management of contained intrathoracic esophageal disruptions. Ann Thorac Surg 1979; 27: 404-408.

12. Lyons WS, Seremetis MG, deGuzman VC, et al. Ruptures and perforations of the esophagus: the case for conservative supportive management. Ann Thorac Surg. 1978; 25:346.

13. Kiernan PD, Sheridan MJ, Elster E, et al. Thoracic esophageal perforations. South Med J. 2003; 96:158 -163.

14. Shaffer HA Jr, Valenzuela G, Mittal RK: Esophageal perforation: a reassessment of the criteria for choosing medical or surgical therapy. Arch Intern Med 1992; 152: 757-761.

15. Tsalis K, Vasiliadis K, Tsachalis T, Christoforidis E, Blouhos K, Betsis D: Management of Boerhaave's syndrome: report of three cases. J Gastrointestin Liver Dis 2008, 17:81-85. 


\section{CASE REPORT}

\section{AUTHORS:}

1. Shenthil Prabhu Murugesan

2. Anbalagan Pinchaimuthu

3. Sentil Kumar Perumal

4. Jeswanth Satyanesan

5. Ravichandran Pallamiappan

\section{PARTICULARS OF CONTRIBUTORS:}

1. Post Graduate, Department of Surgical Gastroenterology, Govt. Stanley Medical College.

2. Assistant Professor, Department of Surgical Gastroenterology, Govt. Stanley Medical College.

3. Assistant Professor, Department of Surgical Gastroenterology, Govt. Stanley Medical College.

FINANCIAL OR OTHER

COMPETING INTERESTS: None
4. Associate Professor, Department of Surgical Gastroenterology, Govt. Stanley Medical College.

5. Professor, Department of Surgical Gastroenterology, Govt. Stanley Medical College.

\section{NAME ADDRESS EMAIL ID OF THE CORRESPONDING AUTHOR:}

Shenthil Prabhu Murugesan, Block Number 601, New SGE Block, Govt. Stanley Medical College, Old Jail Road, Royapuram, Chennai-600001, Tamilnadu. E-mail: mshenthil@rediffmail.com

Date of Submission: 06/10/2015. Date of Peer Review: 07/10/2015. Date of Acceptance: 17/10/2015. Date of Publishing: 29/10/2015. 